Volume 8. No. 8, August 2020

International Journal of Emerging Trends in Engineering Research

Available Online at http://www.warse.org/IJETER/static/pdf/file/ijeter107882020.pdf

https://doi.org/10.30534/ijeter/2020/107882020

\title{
Effect of Antimony Oxide Nanoparticles on Structural, Optical and AC Electrical Properties of (PEO-PVA) Blend for Antibacterial Applications
}

\author{
Ranya Mahmood Mohammed ${ }^{1}$, Majeed Ali Habeeb ${ }^{2}$ and Ahmed Hashim ${ }^{3}$ \\ ${ }^{1}$ University of Babylon, College of Education for Pure Sciences, Department of Physics, Iraq. \\ ranyamahmoud1991@gmail.com \\ ${ }^{2}$ University of Babylon, College of Education for Pure Sciences, Department of Physics, Iraq. \\ :pure.majeed.ali@uobabylon.edu.iq \\ ${ }^{3}$ University of Babylon, College of Education for Pure Sciences, Department of Physics, Iraq. \\ pure.ahmed.hashim@uobabylon.edu.iq, ahmed_taay@yahoo.com
}

\begin{abstract}
In this work, the (PEO-PVA- $\mathrm{Sb}_{2} \mathrm{O}_{3}$ ) nanocomposites were prepared from (PEO-PVA) blend with different concentrations of the $\mathrm{Sb}_{2} \mathrm{O}_{3}$ nanoparticles by using the casting method to used it for different modern applications such as: antibacterial, humidity sensors, solar cells, diodes, thermal energy storage and release ...etc. The structural, optical and dielectric properties of (PEO-PVA-Sb $\mathrm{O}_{3}$ ) nanocomposites have been studied. The results of optical properties for nanocomposites showed that the absorbance has high values at UV region. Also, its increase while the transmittance and energy band gap reduce of (PEO-PVA) blend with the increase in $\mathrm{Sb}_{2} \mathrm{O}_{3}$ nanoparticles concentrations. The absorption coefficient, extinction coefficient, refraction index, dielectric constant and optical conductivity are increased with the increase in $\mathrm{Sb}_{2} \mathrm{O}_{3}$ nanoparticles concentrations. The dielectric properties of nanocomposites showed that the dielectric constant, dielectric loss and A.C electrical conductivity of (PEOPVA) blend increase with the increase in $\mathrm{Sb}_{2} \mathrm{O}_{3}$ nanoparticles concentrations. Also, the dielectric constant and dielectric loss of (PEO-PVA- $\mathrm{Sb}_{2} \mathrm{O}_{3}$ ) nanocomposites decrease while the A.C electrical conductivity increases with the increase in frequency. finally, the (PEO-PVA$\mathrm{Sb}_{2} \mathrm{O}_{3}$ ) nanocomposites tested for antibacterial applications. The results showed that the the (PEO-PVA$\mathrm{Sb}_{2} \mathrm{O}_{3}$ ) nanocomposites have good activity for antibacterial.
\end{abstract}

Key words: Antibacterial, blend, optical properties, conductivity, $\mathrm{Sb}_{2} \mathrm{O}_{3}$, nanocomposites.

\section{1-INTRODUCTION}

Nanocomposites are a major factor in the formation of novel advanced materials suitable for a variety of different applications, such as electrical engineering , nanocomposites have attracted considerable interest in both academia and industry [1]. Nanocomposites have gained much interest recently. Significant efforts are underway to control the nano-structures via innovative synthetic approaches. The properties of nanocomposite materials depend not only on the properties of their individual parents but also on their morphology and interfacial characteristics. The physical, chemical and biological properties of nano materials differ from the properties of individual atoms and molecules or bulk matter. By creating nanoparticles, it is possible to control the fundamental properties of materials, such as their melting temperature, magnetic properties, charge capacity and even their colour with outchanging the materials' chemical compositions[2]. Additives are constituents added to polymers to provide them with specific properties and improve basic properties. These constituents are added in a granular form or as small particles. Nanocomposites can be defined as a composite material in which at least one of the phases (mostly the filler) shows dimensions in the nanometer range, as the filler, size reaches the nanometer level, the interactions at the interfaces become considerably large with respect to the size of the inclusion and thus the final properties show significant changes. A nanocomposite has two parts, filler and the matrix, a traditional composite typically uses a fiber such as carbon fiber or fiberglass as the filler. The properties of nanocomposites are highly dependent on: properties of the filler (geometry, size, filler type), host matrix: (crystallinity, polymer chemistry, nature thermoplastic or thermosetting), surface treatment, interfacial properties, fill grade, degree of dispersion and agglomeration, Relative arrangements and subsequent synergy between constituents and synthesis methods [1,2]. PEO-based polymer electrolytes have been extensively researched to gain additional know ledge $[3,4]$. PEO presents numerous advantageous properties, including good dimensional stability, high ionic conductivity in amorphous form, satisfactory corrosion resistance, cost-effectiveness [5]. On the downside, the ionic conductivity of PEO is low because it contains a high concentration of crystalline phase, which makes it impossible to reach a high DC conductivity [6]. Poly(vinyl alcohol) PVA, is a watersoluble polymer, it has been selected as an organic part for bio composite. PVA membranes are flexible materials and own, high dimensional stability, high transparency and super permeability properties. PVA has been a known semi-crystalline polymer which possesses certain physical properties due to its crystal-amorphous interfacial effect [7]. One of the important classes of polymer electrolytes is pollar polymer like polythylene oxide, polyvinyl alcohol in this paper we have used PVA as ahost polymer because PVA is semi crystalline polymer and has very important 
applications due to the role of oh group and hydrogen bonds[5]. Optical polymers have attracted considerable attention in recent years because of their important industrial applications such: solar cells, diodes, filters of light[8]. Antimony trioxide $\left(\mathrm{Sb}_{2} \mathrm{O}_{3}\right)$ is an inorganic commercial compound and very important on antimony materials family. It is found in nature as valentinite and senarmontite minerals [9]. Like most polymeric oxides, $\mathrm{Sb}_{2} \mathrm{O}_{3}$ is soluble in water with the hydrolysis.Antimony trioxide is used as flame retardant additive. Antimony trioxide is mostly used in plastic (polymer) materials Antimony trioxide available in white stable crystalline powder which consist of $83.53 \%$ antimony and $16.47 \%$ oxygen. It also contains the small quantity of antimony (IV) and antimony (V) which is generated during production [10]. This paper deals with the effect of $\mathrm{Sb}_{2} \mathrm{O}_{3}$ nanoparticles on structural, optical and A.C electrical properties of (PEO-PVA) blend.

\section{2-EXPERIMENTAL}

The (PEO-PVA-Sb $\mathrm{O}_{3}$ ) nanocomposites were prepared from (PEO-PVA) blend with different concentrations of the $\mathrm{Sb}_{2} \mathrm{O}_{3}$ nanoparticles by using the casting method. The (PEO-PVA) blend sample were prepared with PVA 50 wt $\%$ with PEO $50 \mathrm{wt} \%$. The $\mathrm{Sb}_{2} \mathrm{O}_{3}$ nanoparticles were added to the (PEO-PVA) blend with concentrations are $(0$, $1.5,3$ and 4.5) wt.\%. The optical characteristics tested in range of wavelength (200-800) nm by spectrophotometer (UV/1800/ Shimadzu). The dielectric characteristics measured by LCR meter type (HIOKI 3532-50 LCR HI TESTER).

The dielectric constant $(\dot{\varepsilon})$ of nanocomposites is defined by the equation [11]

$\varepsilon^{-}=\mathrm{C}_{\mathrm{p}} / \mathrm{C}_{\mathrm{o}}$

Where, $\mathrm{Cp}$ is parallel capacitance and Co is vacu-um capacitor

The dielectric loss $\left(\varepsilon^{\prime \prime}\right)$ is given by the eqution[11]

$\varepsilon "=\varepsilon \dot{c} \mathrm{D}$

where, D: is dispersion factor of nanocomposites.

The A.C electrical conductivity is determined by the following equation [12]

$\sigma_{\mathrm{A} . C}=\mathrm{W} \varepsilon^{\prime \prime} \varepsilon_{\mathrm{o}}$

Where, $w$ is the angular frequency.

Absorption coefficient $(\alpha)$ iscalculated as the fol- lowing equation[8]:

$\alpha=2.303(\mathrm{~A} / \mathrm{t})$

A: is the absorbance. For amorphous polymers, indirect transition model can be computed as[13]

$\alpha h v=D(h v-E g)^{x}$
Where D is a constant, hv is the photon energy, $\mathrm{E}$ is the optical energy band gap, $\mathrm{x}=3$ for forbidden indirect transition and $\mathrm{x}=2$ for allowed indirect transition.

Refractive index (n) is determined by following equation[14]

$\mathrm{n}=\mathrm{c} / \mathrm{v}$

where (c) is the velocity of the light in vacuum and (v) is the velocity of the light.

The extinction coefficient $(\mathrm{k})$ is determined by the following equation[8]

$\mathrm{k}=\alpha \lambda / 4 \pi$

Where $\lambda$ is the wavelength of incident light.

The dielectric constant is classified into two parts real $\left(\varepsilon_{\mathrm{r}}\right)$, and imaginary $\left(\varepsilon_{\mathrm{im}}\right)$ which are given by the following equations[15],[16].

$\varepsilon_{\mathrm{r}}=\mathrm{n}^{2}-\mathrm{k}^{2}$

$\varepsilon_{\text {im }}=2 \mathrm{nk}$

The optical conductivity $(\sigma)$ has been determined by[17]

$\boldsymbol{\sigma}=\alpha \mathrm{nc} / 4 \pi$

\section{3-RESULTS AND DISCUSSION}

Figure 1 shows the variation of the optical absorbance spectra of (PEO-PVA- $\mathrm{Sb}_{2} \mathrm{O}_{3}$ ) nanocomposites with photon wavelength for different concentrations of $\mathrm{Sb}_{2} \mathrm{O}_{3}$ nanoparticles. The (PEO-PVA- $\mathrm{Sb}_{2} \mathrm{O}_{3}$ ) nanocomposites have high absorbance at UV region. These are consistent with the results [18-26]. Figure 2 shows that transmittance spectrum as a function of wavelength for (PEO-PVA$\mathrm{Sb}_{2} \mathrm{O}_{3}$ ) nanocomposites. From these figures that absorbance increases and transmittance decreases with the increase in the concentration of $\mathrm{Sb}_{2} \mathrm{O}_{3}$ nanoparticles which is related to the increase the number of charges carries[27], as shown in Figure 3. The variation of the absorption coefficient of the nanocomposites with photon energy is shows in Figure 4. From this figure, it can be seen that the absorption coefficient is increased with increasing of the $\mathrm{Sb}_{2} \mathrm{O}_{3}$ concentration which may be due to the absorption by the impurities. The absorption coefficient is smaller and stable in the low photon energy because of the scattering of the photon energy [28]. Figures 5 and 6 show the energy band gap of nanocomposites. From the values of the absorption coefficient, it can be concluded that the nanocomposites have indirect energy band gap. The energy band gap decreases with increasing the $\mathrm{Sb}_{2} \mathrm{O}_{3}$, this attributed to decrease the distant between the conduction band and valance band with the increase $\mathrm{Sb}_{2} \mathrm{O}_{3}$ concentration[28]. Figure 7 represents the extinction coefficient of nanocomposites as a function of the photon wavelength. The extinction coefficient indicates the amount of absorption loss when electromagnetic wave propagates through a material, which is a measure of the fraction of light lost owing to the scattering and absorption per unit distance of a penetration medium. The extinction coefficient is directly related to the absorption of a 
material and to the absorption coefficient. From Figure 8, the exponential decrease in the extinction coefficient with an increase in the photon energy represents that the fraction of light lost owing to the scattering and absorbance increases. In addition, the loss factor decreases, as the photon energy increases. Figure 8 shows the relationship between the refractive index of nanocomposites and the wavelength. It can be observed that the refractive index of an as-synthesized material decreases, as the photon energy increases. This reflects that the synthesized polymeric samples represent the normal dispersion behavior. The variation in refractive index values with the photon energy shows that the interaction between a photon and electrons takes place. Thus, one can get the desired material for fabricating the optoelectronics devices, by estimating the photon energy, as the internal energy of a device depends on the photon energy. The decrease in the extinction coefficient and refractive index with an increase in the photon energy may be correlated with an increase in the absorption coefficient and a decrease in the transmittance [29]. Figures 9 and 10 show the relationship between the real, imaginary parts of dielectric constant with wavelength of different concentrations of $\mathrm{Sb}_{2} \mathrm{O}_{3}$ nanoparticles. From these figures, we can see that the real and imaginary parts of dielectric constant are increasing with the increase in the $\mathrm{Sb}_{2} \mathrm{O}_{3}$ nanoparticles concentrations which is attributed to increase in the absorption coefficient and scattering [30]. The optical conductivity of (PEO-PVA-Sb ${ }_{2} \mathrm{O}_{3}$ ) nanocomposites is shown in Figure 11. This figure shows that the optical conductivity of all samples of nanocomposites is decreased with the increasing of the wavelength, this behavior attributed to the optical conductivity depends strongly on the wavelength of the radiation incident on the samples of nanocomposites; the increase of optical conductivity at low wavelength of photon is due to high absorbance of all samples of nanocomposites in that region, hence, increase of the charge transfer excitations. The optical conductivity spectra indicated that the samples are transmittance within the visible and near infrared regions. Also, the optical conductivity of nanocomposites is increased with the increase of $\mathrm{Sb}_{2} \mathrm{O}_{3}$ nanoparticles concentrations, this behavior related to the creation of localized levels in the energy gap; the increase of $\mathrm{Sb}_{2} \mathrm{O}_{3}$ nanoparticles concentrations increasing the density of localized stages in the band structure, hence, increase of the absorption coefficient consequently increasing the optical conductivity of nanocomposites [31]. Figures 12 and 13 show the observed variations of dielectric parameters (dielectric constant and loss) with frequency at room temperature. From the figures, it clear that at lower frequencies the values of both dielectric constant and dielectric loss are high because of the fact that in this region the dipoles have sufficient time to orient themselves in the direction of the applied electric field. In addition to this, due to the electronic polarization effect (space charge polarization), charge carriers are accumulated at the electrode and electrolyte interface. As frequency increases dielectric constant and loss decreases monotonically and attains a constant value. This change in dielectric property is due to the fact that as the frequency increases, space charge polarization drops and more number of ions cannot diffuse in the direction of the applied electric field as a result the charge carriers are less contributed to the dielectric property. This change confirms the non-Debye type behavior of polymer electrolytes. Hence, due to insufficient time, the dipoles are unable to follow the field variation at higher frequencies [32]. The dielectric constant and dielectric loss decrease with the increase of $\mathrm{Sb}_{2} \mathrm{O}_{3}$ nanoparticles concentration, this result can be attributed to the increase in conductivity as a result of the increase charge carrier density in polymer matrix [33,34]. Figure14 shows the variation of the A.C electrical conductivity of (PEO-PVA- $\mathrm{Sb}_{2} \mathrm{O}_{3}$ ) nanocomposites with frequency. This figure shows that the A.C electrical conductivity increases when increasing the frequency, this behavior can be attributed to the interfacial polarization. The A.C electrical conductivity increases with an increase in $\mathrm{Sb}_{2} \mathrm{O}_{3}$ nanoparticles concentrations which is due to increase of the charge carrier density in polymer matrix [35-37]. The antibacterial properties of the (PEO-PVA$\mathrm{Sb}_{2} \mathrm{O}_{3}$ ) nanocomposites tested against E. coli. Figure 15 shows the antibacterial activity for (PEO-PVA-Sb $\mathrm{O}_{3}$ ) nanocomposites. As shown in Figure 15, the inhibition zone diameter increases with increase in $\mathrm{Sb}_{2} \mathrm{O}_{3}$ nanoparticles concentration. The reason for the antibacterial activity of nanocomposites may be due to the presence of reactive oxygen species (ROS) generated by different nanoparticles. Chemical interaction between hydrogen peroxide and membrane proteins or between the chemical produced in the presence of nanocomposites and the outer bilayer of bacteria could be the reason for the antibacterial activity of nanocomposites. The hydrogen peroxide produced enters the cell membrane of bacteria and kills them. The nanocomposites continue to be in interaction with dead bacteria once the hydrogen peroxide is generated; thus foiling further bacterial action and continue to produce and release hydrogen peroxide to the medium. The possible mechanism of action is that the nanoparticles in nanocomposites are ing the negative charges which create the electromagnetic attraction between the nanoparticles and the microbes. When the attraction is made, the microbes get oxidized and die instantly. The main mechanism that caused the antibacterial of nanocomposites by the nanoparticles might be through oxidative stress caused by ROS. ROS includes radicals like superoxide radicals $\left(\mathrm{O}^{-2}\right)$, hydroxyl radicals $(-\mathrm{OH})$ and hydrogen peroxide $\left(\mathrm{H}_{2} \mathrm{O}_{2}\right)$; and singlet oxygen $\left({ }^{1} \mathrm{O}_{2}\right)$ could be the reason damaging the proteins and DNA in the bacteria. ROS could have been produced by the present metal oxide leading to the inhibition of most pathogenic bacteria [38].

\section{CONCLUSIONS}

The optical properties results showed that the absorbance, absorption coefficient, extinction coefficient, refractive index, dielectric constant (real, imaginary) and optical conductivity of (PEO-PVA) blend are increased while the transmittance and energy band gap are decreased with increasing of the $\mathrm{Sb}_{2} \mathrm{O}_{3}$ nanoparticles concentrations..The results of dielectric properties indicated that the dielectric constant, dielectric loss and A.C electrical conductivity of (PEO-PVA) blend are increased with increasing of the $\mathrm{Sb}_{2} \mathrm{O}_{3}$ nanoparticles concentrations. The dielectric constant and dielectric loss of nanocomposites are decreased while the A.C electrical conductivity is increases with increasing of the frequency. The results of 
antibacterial activity showed that the inhibition zone diameter increases with increase in $\mathrm{Sb}_{2} \mathrm{O}_{3}$ nanoparticles concentrations

\section{REFERENCES}

1. C. Sun, "Controlling the rheology of polymer/silica nanocomposites." PhD dissertation, Eindhoven University of Technology, 2010.

2. C. C. Okpala, "Nanocomposites-an overview," Int. J. Eng. Res. Dev., vol. 8, no. 11, pp. 17-23, 2013.

3. W. Li, Y. Pang, J. Liu, G. Liu, Y. Wang, and Y. Xia, "A PEO-based gel polymer electrolyte for lithium ion batteries," Rsc Adv., vol. 7, no. 38, pp. 23494-23501, 2017.

4. V. M. Mohan, P. B. Bhargav, V. Raja, A. K. Sharma, and V. V. R. Narasimha Rao, "Optical and electrical properties of pure and doped PEO polymer electrolyte films," Soft Mater., vol. 5, no. 1, pp. 33-46, 2007.

5. K. S. Ngai, S. Ramesh, K. Ramesh, and J. C. Juan, “A review of polymer electrolytes: fundamental, approaches and applications," Ionics (Kiel)., vol. 22, no. 8, pp. 1259-1279, 2016.

6. T. Itoh, Y. Ichikawa, T. Uno, M. Kubo, and O. Yamamoto, "Composite polymer electrolytes based on poly (ethylene oxide), hyperbranched polymer, BaTiO3 and LiN (CF3SO2) 2," Solid State Ionics, vol. 156, no. 3-4, pp. 393-399, 2003.

7. H. M. Ahmad, S. H. Sabeeh, and S. A. Hussen, "Electrical and optical properties of PVA/LiI polymer electrolyte films," Asian Trans. Sci. Technol., vol. 1, no. 6, pp. 16-20, 2012.

8. Angham.G.Hadi, Farhan Lafta, Ahmed Hashim, Hussein Hakim, Abbas I. O. Al-Zuheiry, Saba R. Salman, Hind Ahmed, Study the Effect of Barium Sulphate on Optical Properties of Polyvinyl Alcohol (PVA), Universal Journal of Materials Science 1(2): 52-55, 2013, DOI: 10.13189/ujms.2013.010207.

9. R. O. Aly, M. M. Hassan, J. A. Hasanen, and E. S. F. El Sayed, "Impact of antimony trioxide on the physico-mechanical and flammability properties of irradiated recycled rubber powder and waste polyethylene composites," J. Appl. Polym. Sci., vol. 124, no. 5, pp. 4098-4106, 2012.

10. E. M. Abdelrazek, A. M. Abdelghany, and A. E. Tarabih, "Characterization and physical properties of silver/PVA nano-composite," Res. J. Pharm. Biol. Chem. Sci., vol. 3, no. 4, p. 448, 2012.

11. H. H. Güllü and D. E. Yıldız, "Frequency dependent dielectric properties of $\mathrm{ZnSe} / \mathrm{p}-\mathrm{Si}$ diode," Politek. Derg., vol. 22, no. 1, pp. 63-67, 2019.

12. K. Praveenkumar, T. Sankarappa, J. S. Ashwajeet, and R. Ramanna, "Dielectric and AC conductivity studies in PPy-Ag nanocomposites," J. Polym., vol. 2015, 2015.

13. T. Siddaiah, P. Ojha, N. O. Kumar, and C. Ramu, "Structural, optical and thermal characterizations of PVA/MAA: EA polyblend films," Mater. Res., vol. 21, no. 5, 2018.

14. J. H. Nahida, "Spectrophotometric analysis for the UV-irradiated (PMMA)," Int. J. Basic Appl. Sci, vol. 12, no. 2, pp. 58-67, 2012.

15. F. I. Ezema, P. U. Asogwa, A. B. C. Ekwealor, P. E. Ugwuoke, and R. U. Osuji, "GROWTH AND
OPTICAL PROPERTIES OF Ag," J. Univ. Chem. Technol. Metall., vol. 42, no. 2, pp. 217-222, 2007.

16. O. G. Abdullah and D. S. Muhammad, "Physical properties of pure and copper oxide doped polystyrene films," Int. J. Mater. Sci., vol. 5, no. 4, pp. 537-545, 2010.

17. R. Tintu, K. Saurav, K. Sulakshna, V. P. N. Nampoori, P. Radhakrishnan, and S. Thomas, "Ge28Se60Sb12/PVA composite films for photonic applications," J. Non-Oxide Glas., vol. 2, no. 4, pp. 167-174, 2010.

18. Falah Ali Jasim, Farhan Lafta, Ahmed. Hashim, Majeed Ali, Angham. G. Hadi, Characterization of palm fronds-polystyrene composites, Journal of Engineering and Applied Sciences, Vol.8, No.5, PP. 140-142, 2013.

19. Farhan Lafta Rashid, Ahmed Hashim, Majeed Ali Habeeb, Saba R. Salman, Hind Ahmed, Preparation of PS-PMMA copolymer and study the effect of sodium fluoride on its optical properties, Journal of Engineering and Applied Sciences, Vol.8 , No.5, PP. 137-139, (2013).

20. A. Hashim, M. A. Habeeb, A. Khalaf, and A. Hadi, Fabrication of (PVA-PAA) Blend-Extracts of Plants Bio-Composites and Studying Their Structural, Electrical and Optical Properties for Humidity Sensors Applications, Sensor Letters, Vol.15, PP. 589-596, doi:10.1166/s1.2017.3856, (2017).

21. Qayssar M. Jebur, Ahmed Hashim, Majeed A. Habeeb, Structural, Electrical and Optical Properties for (Polyvinyl Alcohol-Polyethylene OxideMagnesium Oxide) Nanocomposites for Optoelectronics Applications, Transactions on Electrical and Electronic Materials, https://doi.org/10.1007/s42341-019-00121-x, (2019).

22. Ahmed Hashim and Majeed Ali Habeeb, Synthesis and Characterization of Polymer Blend-CoFe ${ }_{2} \mathrm{O}_{4}$ Nanoparticles as a Humidity Sensors For Different Temperatures, Transactions on Electrical and Electronic Materials, DOI: 10.1007/s42341-018-00811, (2019).

23. Ahmed Hashim, Majeed Ali Habeeb, and Aseel Hadi, Synthesis of Novel Polyvinyl Alcohol-Starch-Copper Oxide Nanocomposites for Humidity Sensors Applications with Different Temperatures, Sensor Letters, Vol.15, No.9, PP.758-761, doi:10.1166/sl.2017.3876, (2017).

24. Ahmed Hashim and Majeed Ali Habeeb, Structural and Optical Properties of (Biopolymer Blend-Metal Oxide) Bionanocomposites For Humidity Sensors, Journal of bionanoscience, Vol.12, No.5, (2018), DOI: https://doi.org/10.1166/jbns.2018.1578.

25. A. Hashim, M. A. Habeeb, A. Hadi, Q. M Jebur, W. Hadi, Fabrication of Novel (PVA-PEG-CMC-Fe3O4) Magnetic Nanocomposites for Piezoelectric Applications, Sensor Letters, Vol.15, No.12, (2017), DOI: https://doi.org/10.1166/s1.2017.3935.

26. M. A. Habeeb, A. Hashim, and A. Hadi, Fabrication of New Nanocomposites: CMC-PAA-PbO Nanoparticles for Piezoelectric Sensors and Gamma Radiation Shielding Applications, Sensor Letters, Vol.15, No.9, PP. 785-790, (2017), DOI: https://doi.org/10.1166/sl.2017.3877. 
27. Noor Hayder, Majeed Ali Habeeb and Ahmed Hashim, Structural, Optical and Dielectric Properties of (PS- $\mathrm{In}_{2} \mathrm{O}_{3} / \mathrm{ZnCoFe}_{2} \mathrm{O}_{4}$ ) Nanocomposites, Egypt. J. Chem, Vo.63, Special Issue (Part 2), Innovation in Chemistry, (2020), 10.21608/ejchem.2019.14646.1887.

28. Majeed Habeeb, Ahmed Hashim , Noor Hayder, Structural and Optical Properties of Novel (PSCr2O3/ ZnCoFe2O4) Nanocomposites For UV and Microwave Shielding, Vo.63, Special Issue (Part 2), Innovation in Chemistry, (2020), DOI: 10.21608/EJCHEM.2019.12439.1774.

29. Basim Abbas, Ahmed Hashim, Novel X-rays attenuation by ( PMMA-PS-WC) New Nanocompsites: Fabrication, Structural, Optical Characterizations and X-Ray Shielding Application, International Journal of Emerging Trends in Engineering Research, Vol.7, No. 8, (2019), https://doi.org/10.30534/ijeter/2019/06782019.

30. Khalid H. H. Al-Attiyah, Ahmed Hashim, Sroor Fadhil Obaid, Fabrication of novel (carboxy methyl cellulose-polyvinylpyrrolidone-polyvinyl

alcohol)/lead oxide nanoparticles: structural and optical properties for gamma rays shielding applications, International Journal of Plastics Technology. (2019); Vol.23, No.1, https://doi.org/10.1007/s12588-019-09228-5.

31. Hind Ahmed, Hayder M. Abduljalil, Ahmed Hashim, Analysis of Structural, Optical and Electronic Properties of Polymeric Nanocomposites/Silicon Carbide for Humidity Sensors, Transactions on Electrical and Electronic Materials, (2019); https://doi.org/10.1007/s42341-019-00100-2.

32. Aseel Hadi, Ahmed Hashim, Yahya Al-Khafaji, Structural, Optical and Electrical Properties of PVA/PEO/SnO2 New Nanocomposites for Flexible Devices, Transactions on Electrical and Electronic
Materials, Vol.21, PP. 283-292, (2020), https://doi.org/10.1007/s42341-020-00189-w.

33. Ahmed Hashim, Majeed A. Habeeb and Qayssar M. Jebur, Structural, Dielectric and Optical properties for (Polyvinyl Alcohol-Polyethylene Oxide- Manganese Oxide) Nanocomposites, Egypt. J. Chem., Vo.63, Special Issue (Part 2), Innovation in Chemistry, (2020), DOI: 10.21608/ejchem.2019.14849.1901.

34. Qayssar M. Jebur, Ahmed Hashim, Majeed A. Habeeb, Structural, A.C electrical and Optical properties of (Polyvinyl alcohol-Polyethylene OxideAluminum Oxide) Nanocomposites for Piezoelectric Devices, Egypt. J. Chem., Vo.63, Special Issue (Part 2), Innovation in Chemistry, (2020), DOI: 10.21608/ejchem.2019.14847.1900.

35. Majeed Ali Habeeb, Ahmed Hashim and Noor Hayder, Fabrication of (PS- $\left.\mathrm{Cr}_{2} \mathrm{O}_{3} / \mathrm{ZnCoFe}_{2} \mathrm{O}_{4}\right)$ Nanocomposites and Studying their Dielectric and Fluorescence Properties for IR Sensors, Egypt. J. Chem., Vo.63, Special Issue (Part 2), Innovation in Chemistry, (2020), DOI: 10.21608/ejchem.2019.13333.1832.

36. Qayssar M. Jebur, Ahmed Hashim, Majeed A. Habeeb, Fabrication, Structural and Optical properties for (Polyvinyl Alcohol-Polyethylene Oxide- Iron Oxide) Nanocomposites, Egypt. J. Chem., Vol. 63, No.2 , pp 611-623, (2020), DOI: 10.21608/EJCHEM.2019.10197.1669.

37. Majeed Ali Habbeb, Ahmed Hashim, Abdul-Raheem K. AbidAli, The dielectric properties for (PMMALiF) composites, European Journal of Scientific Research, Vol. 61, No.3, pp.367-371, (2011).

38. Ahmed Hashim, Hayder M. Abduljalil, and Hind Ahmed, Fabrication and Characterization of (PVATiO2)1-x/ SiCx Nanocomposites for Biomedical Applications, Egypt. J. Chem., Vol.63, No.1, pp. 71 83, (2020), DOI: 10.21608/ejchem.2019.10712.1695. 


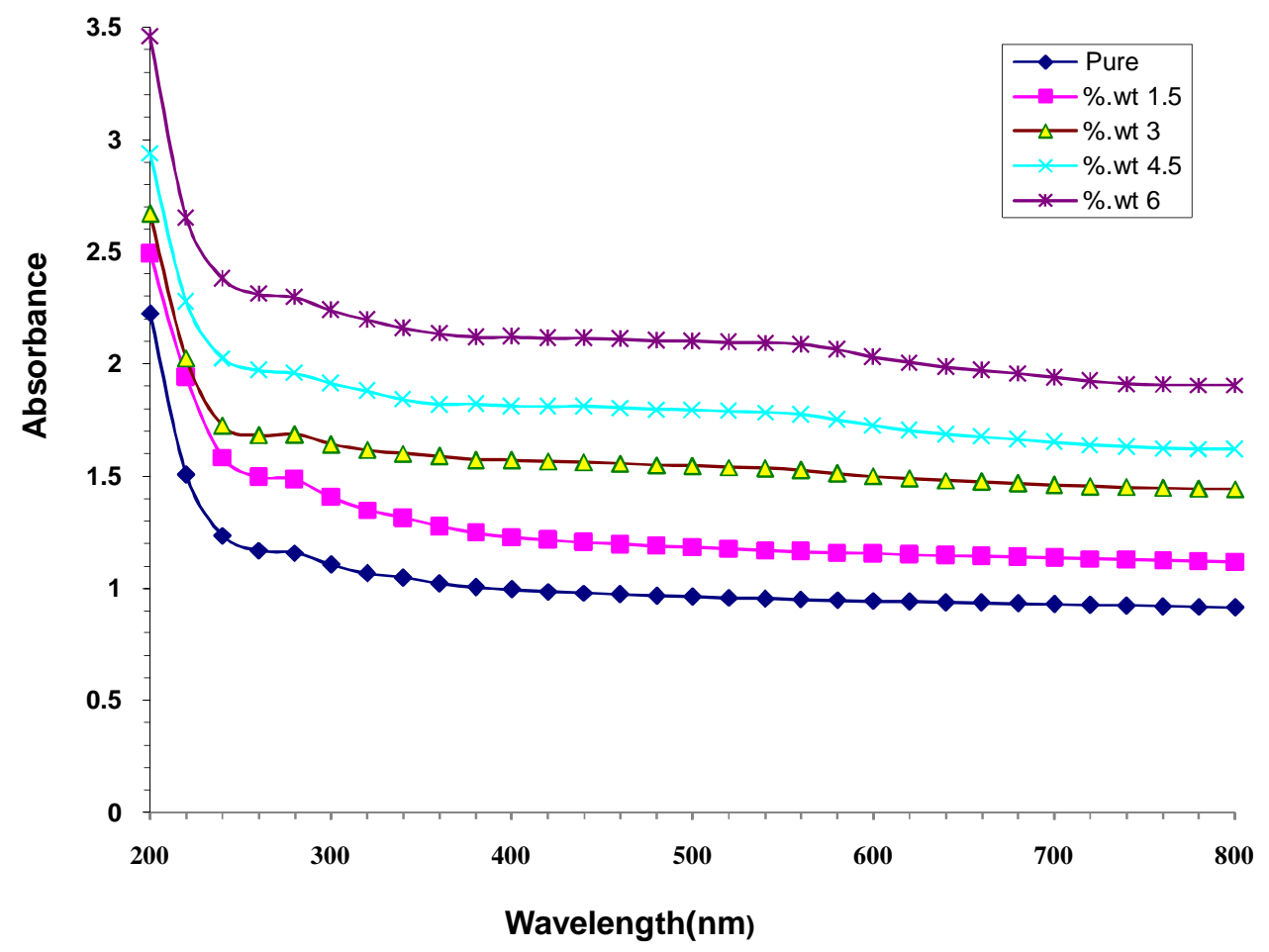

Figure 1: variation absorbance for (PEO-PVA-Sb $\left.\mathrm{O}_{3}\right)$ nanocomposites with wavelength.

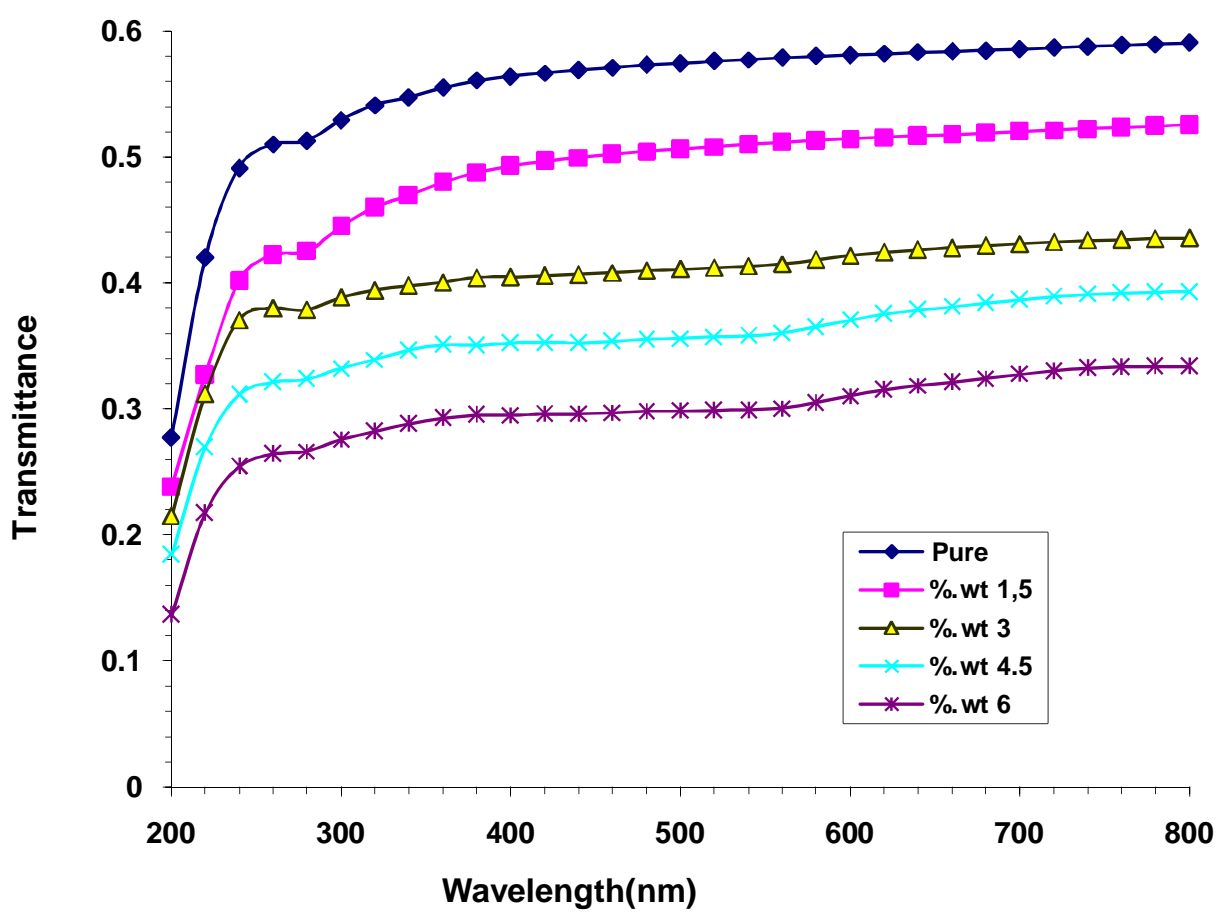

Figure 2: variation of Transmittance for (PEO-PVA-Sb $\mathrm{O}_{3}$ ) nanocomposites with wavelength. 
Ranya Mahmood Mohammed et al., International Journal of Emerging Trends in Engineering Research, 8(8), August 2020, 4726 - 4738
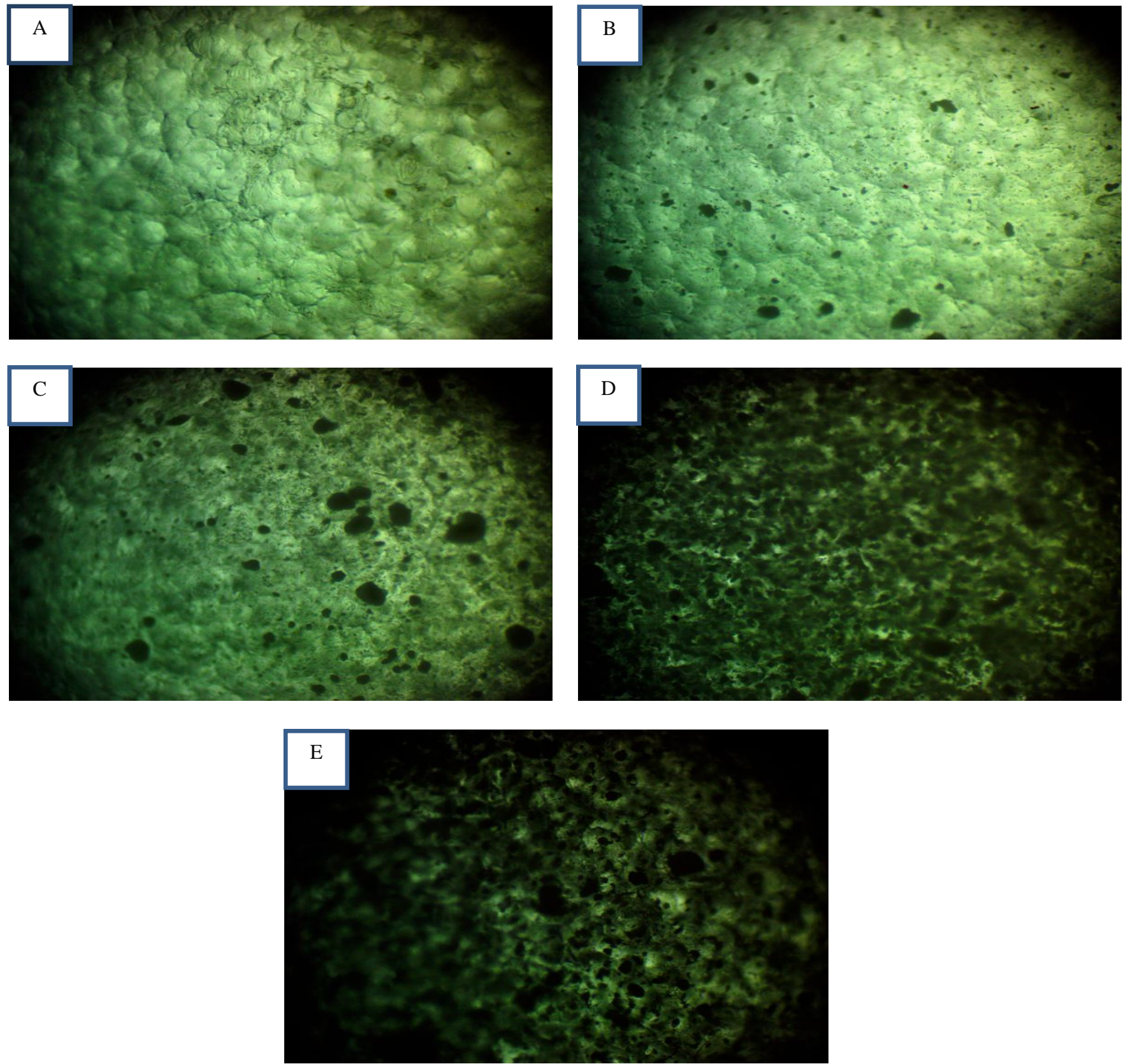

Figure 3: photomicrographs for (PEO-PVA- $\mathrm{Sb}_{2} \mathrm{O}_{3}$ )nanocomposites (A) for (PEO-PVA) blend, (B) for $1.5 \mathrm{wt} \% \mathrm{Sb}_{2} \mathrm{O}_{3}$ nanoparticles, (C) for 3 wt. $\% \mathrm{Sb}_{2} \mathrm{O}_{3}$ nanoparticles, (D) for $4.5 \mathrm{wt} \% \mathrm{Sb}_{2} \mathrm{O}_{3}$ nanoparticles, (E) for $6 \mathrm{wt} \% \mathrm{Sb}_{2} \mathrm{O}_{3}$ nanoparticles . 
Ranya Mahmood Mohammed et al., International Journal of Emerging Trends in Engineering Research, 8(8), August 2020, 4726 - 4738

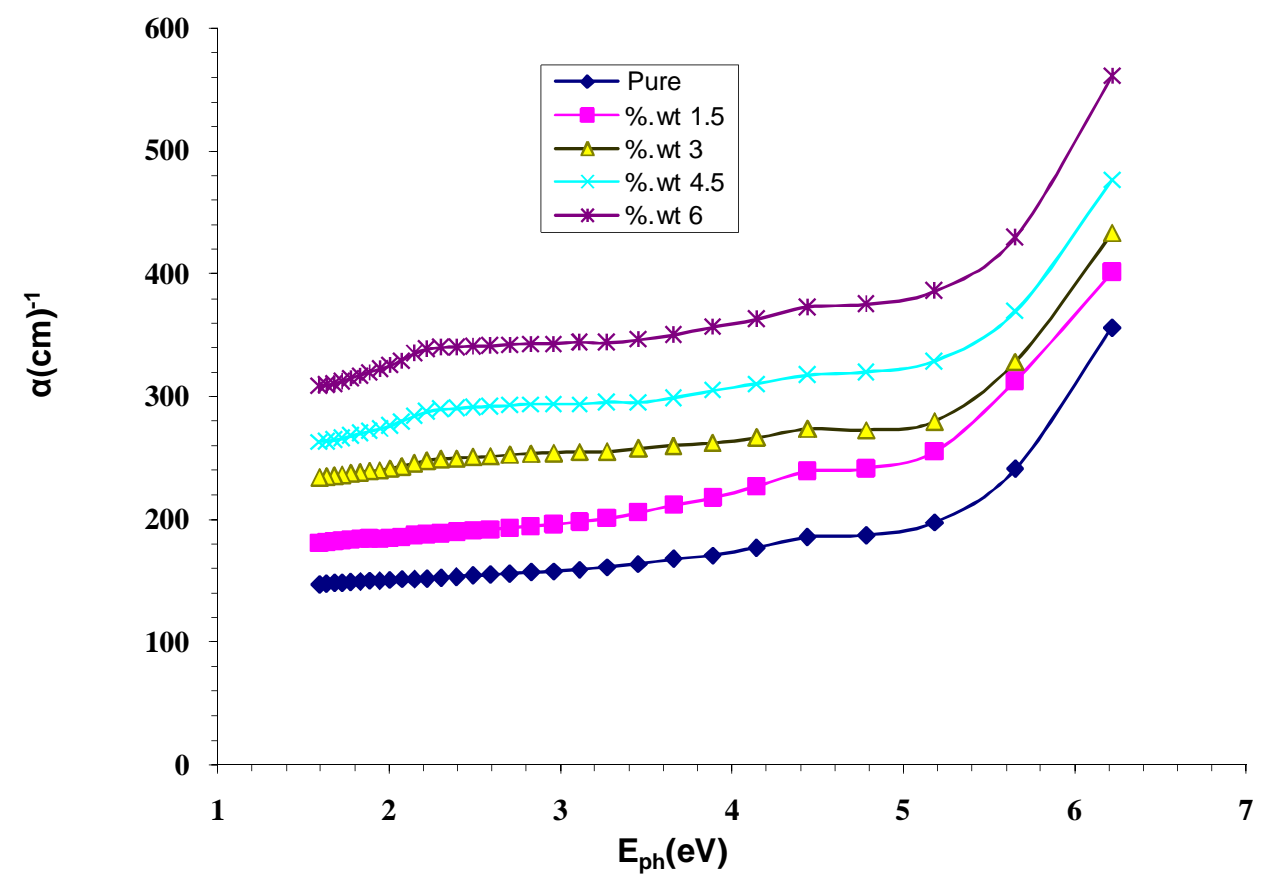

Figure 4: variation of absorption coefficient $(\alpha)$ for $\left(\mathrm{PEO}-\mathrm{PVA}-\mathrm{Sb}_{2} \mathrm{O}_{3}\right)$ nanocomposites with photon energy.

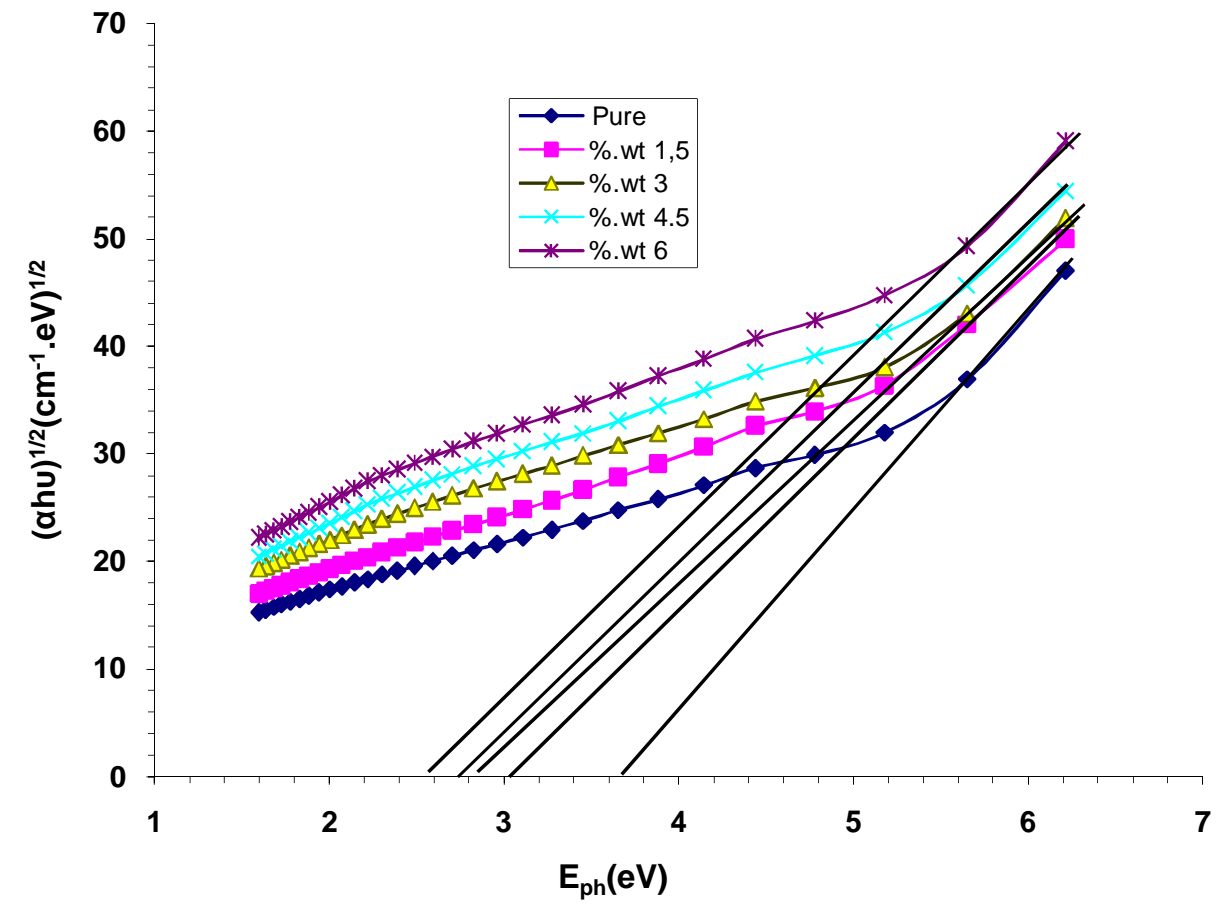

Figure 5: variation of $(\alpha h v)^{1 / 2}$ for (PEO-PVA- $\left.\mathrm{Sb}_{2} \mathrm{O}_{3}\right)$ nanocomposites with photon energy. 


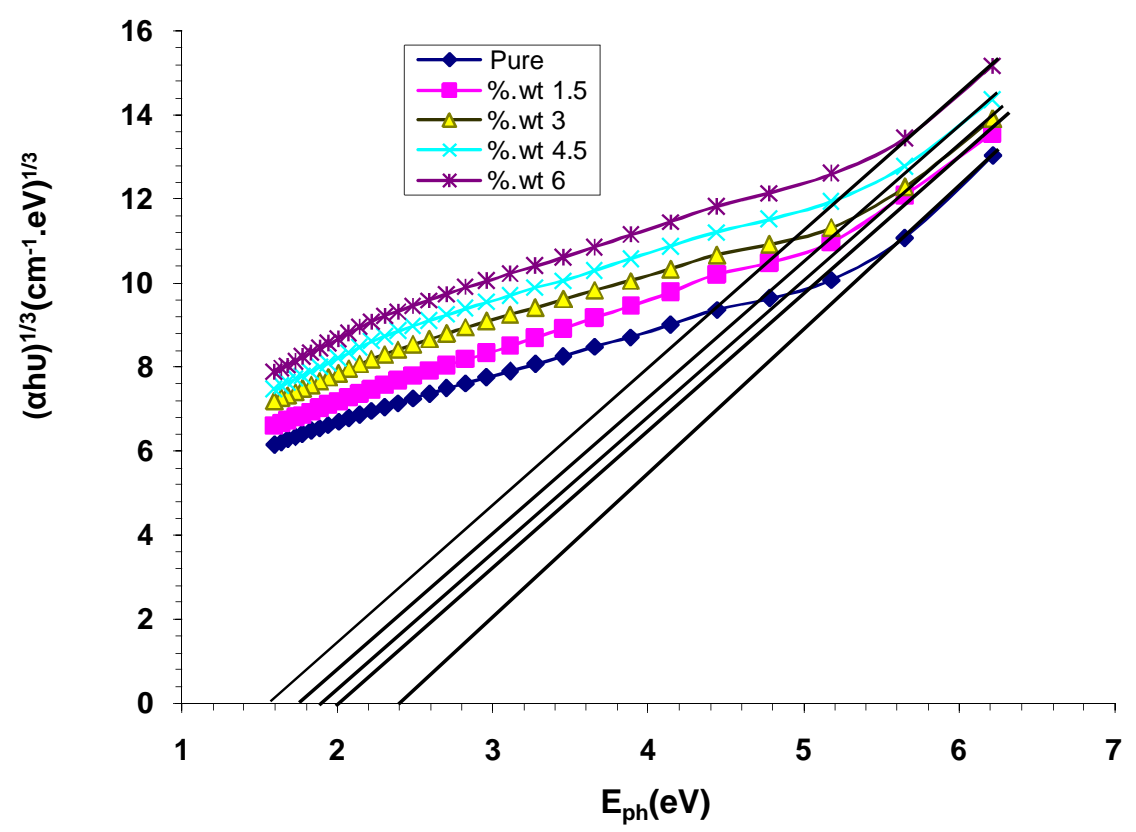

Figure 6: variation of $(\alpha h v)^{1 / 3}$ for $\left(\mathrm{PEO}-\mathrm{PVA}-\mathrm{Sb}_{2} \mathrm{O}_{3}\right)$ nanocomposites with photon energy.

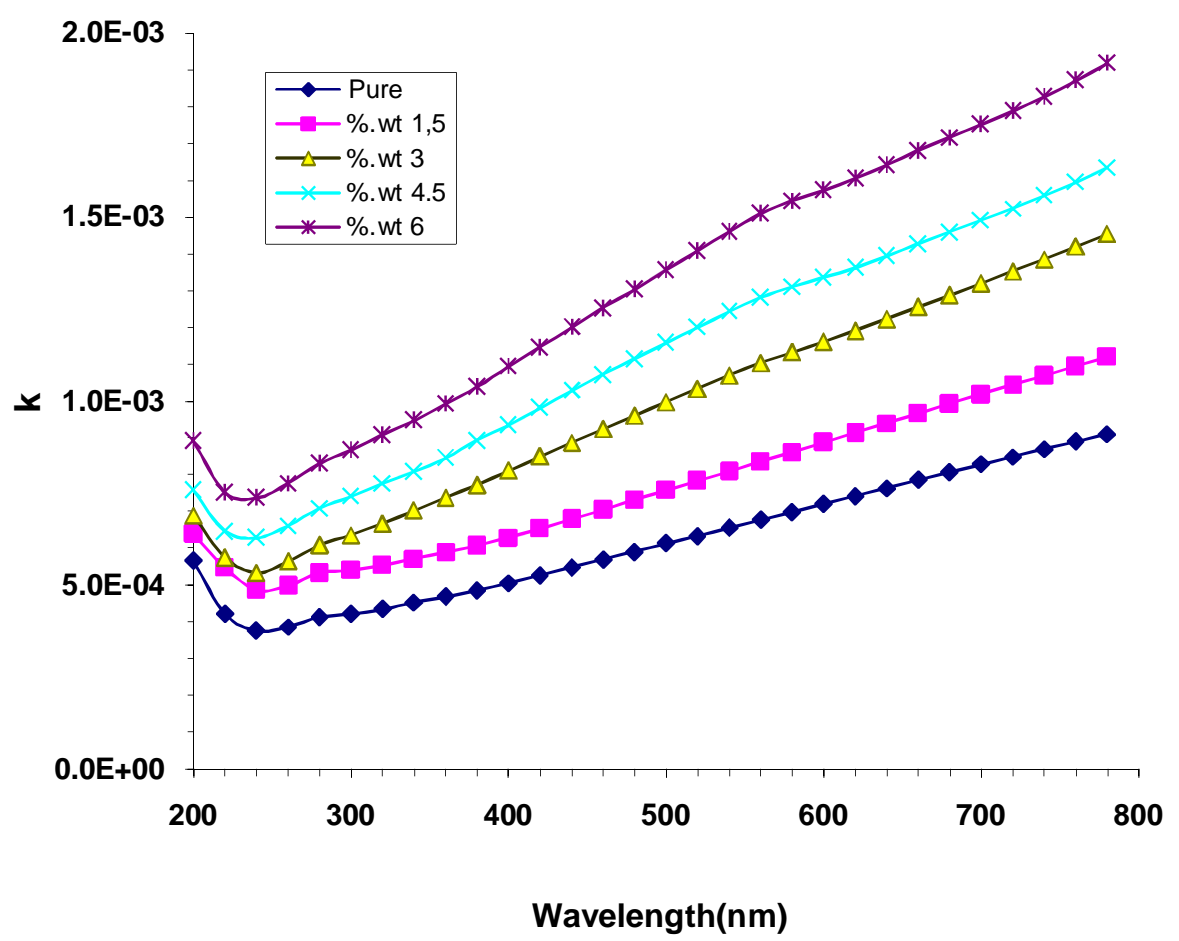

Figure 7: variation of extinction coefficient for ( $\left.\mathrm{PEO}-\mathrm{PVA}-\mathrm{Sb}_{2} \mathrm{O}_{3}\right)$ nanocomposite with wavelength. 


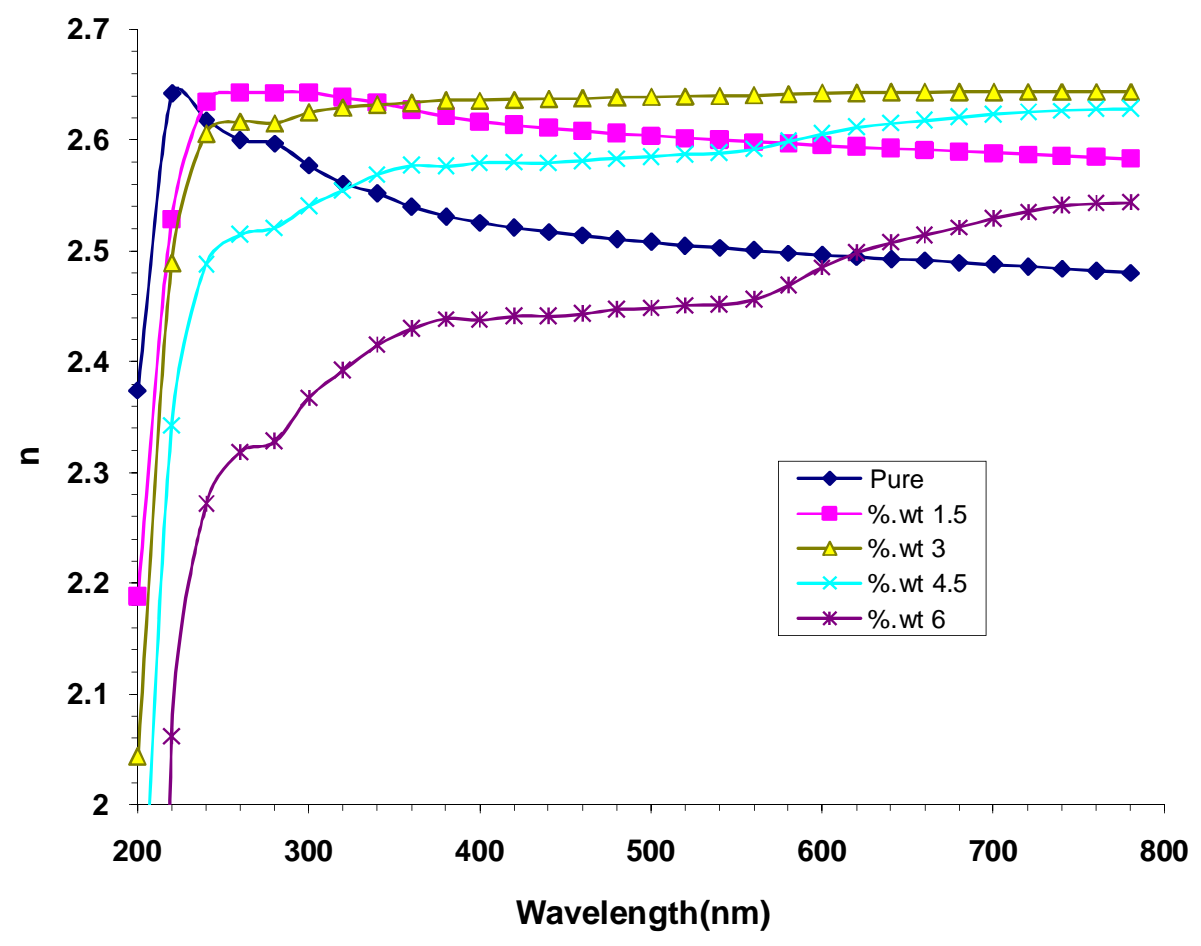

Figure 8: variation of refractive index for (PEO-PVA- $\mathrm{Sb}_{2} \mathrm{O}_{3}$ ) nanocomposites with wavelength.

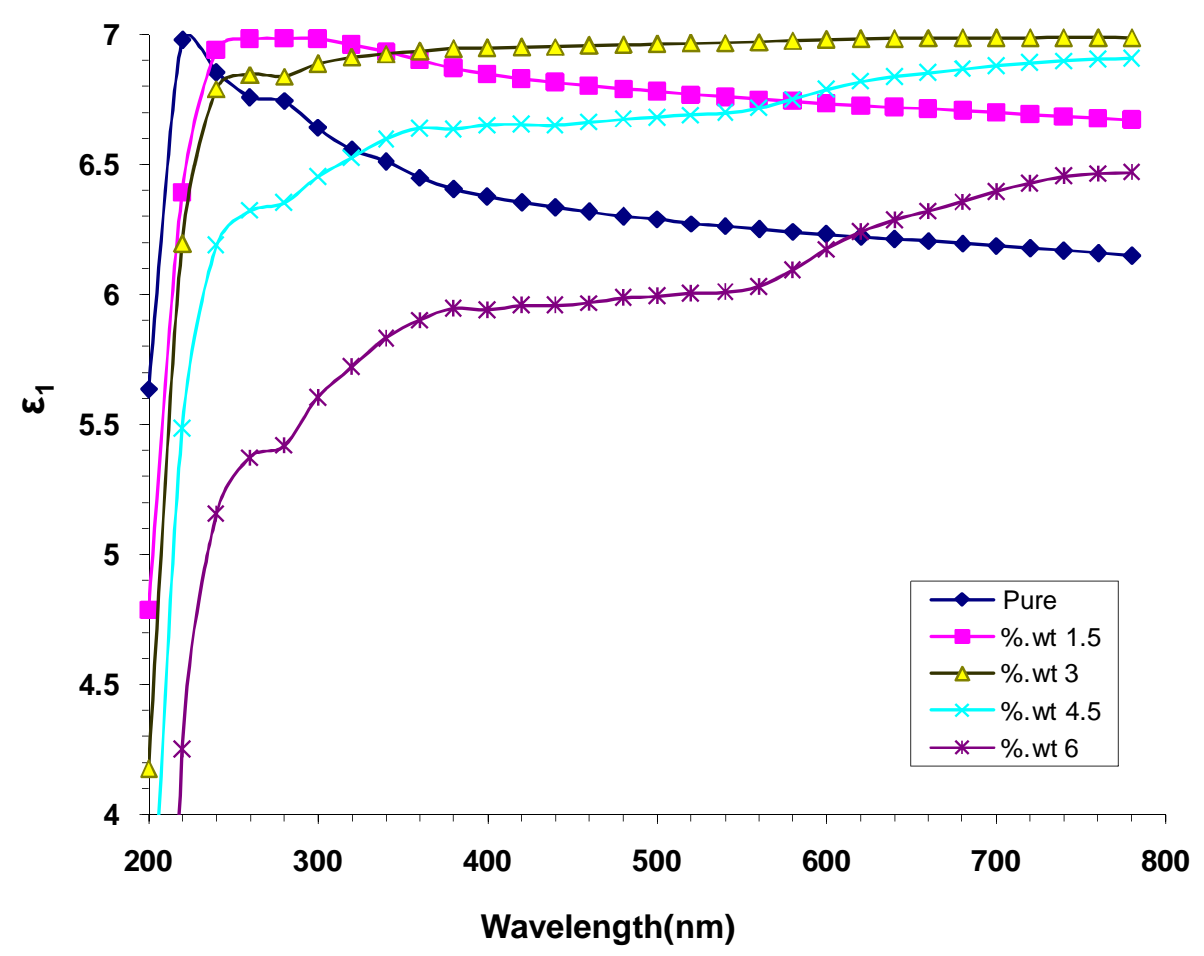

Figure 9: Variation of real part of dielectric constant for (PEO-PVA- $\mathrm{Sb}_{2} \mathrm{O}_{3}$ ) nanocomposites with wavelength. 


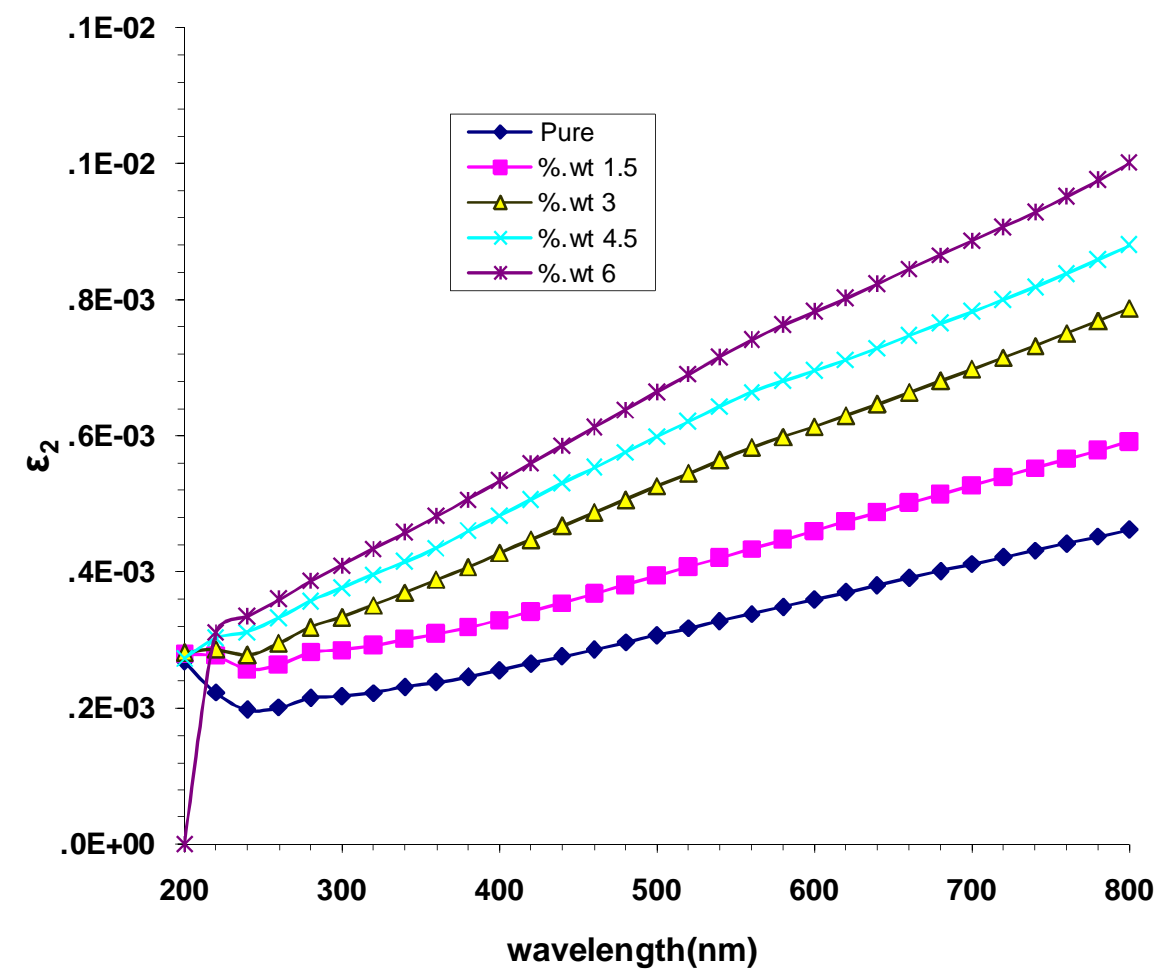

Figure 10: variation of imaginary part of dielectric constant for (PEO-PVA- $\mathrm{Sb}_{2} \mathrm{O}_{3}$ ) nanocomposites with wavelength.

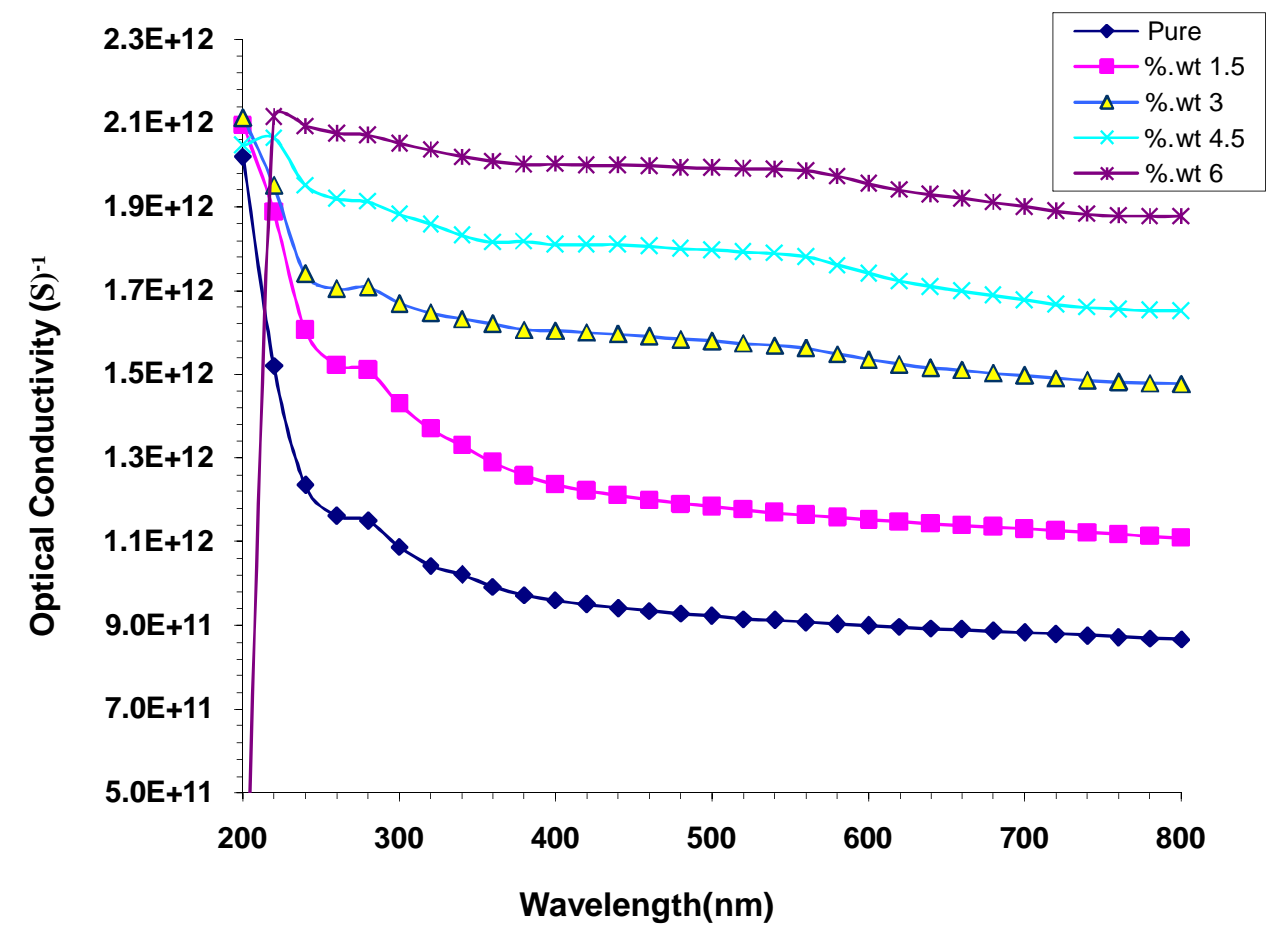

Figure 11: variation of optical conductivity for (PEO-PVA- $\mathrm{Sb}_{2} \mathrm{O}_{3}$ ) nanocomposites with wavelength. 


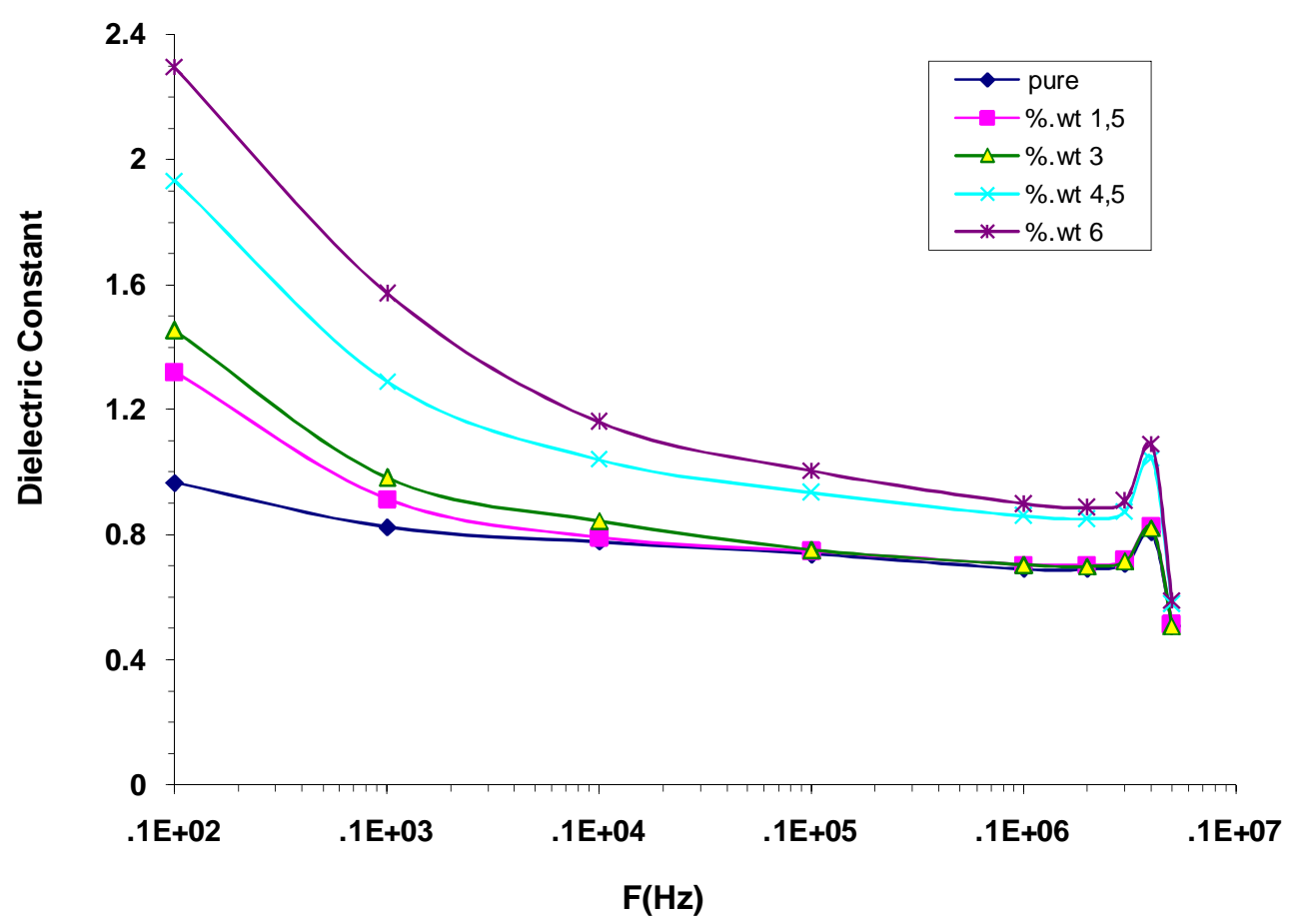

Figure 12: variation of dielectric constant for ( $\mathrm{PEO}-\mathrm{PVA}-\mathrm{Sb}_{2} \mathrm{O}_{3}$ ) nanocomposites with frequency.

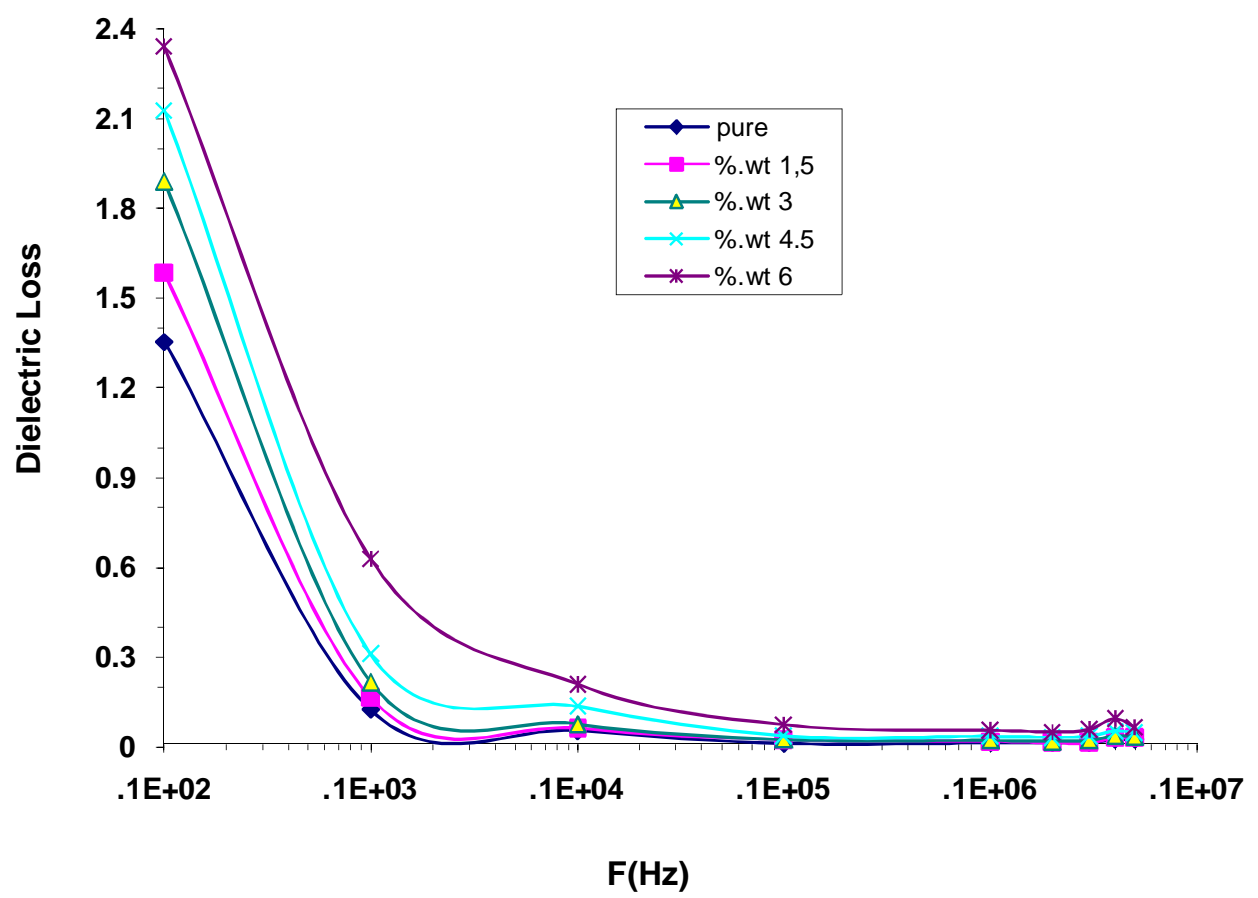

Figure 13: variation of dielectric loss for (PEO-PVA- $\mathrm{Sb}_{2} \mathrm{O}_{3}$ ) nanocomposites with frequency. 


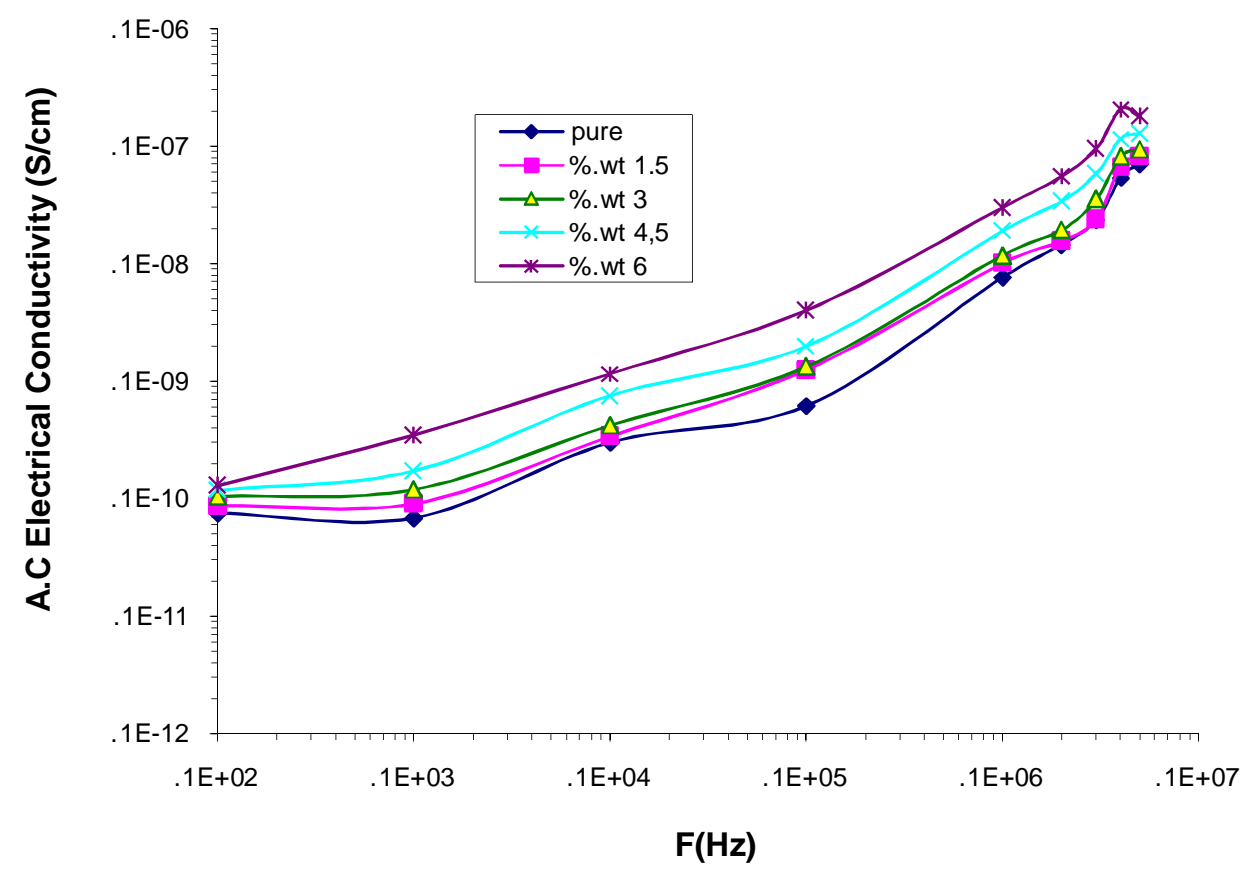

Figure 14: variation of A.C electrical conductivity for ( $\left.\mathrm{PEO}-\mathrm{PVA}-\mathrm{Sb}_{2} \mathrm{O}_{3}\right)$ nanocomposites with frequency.

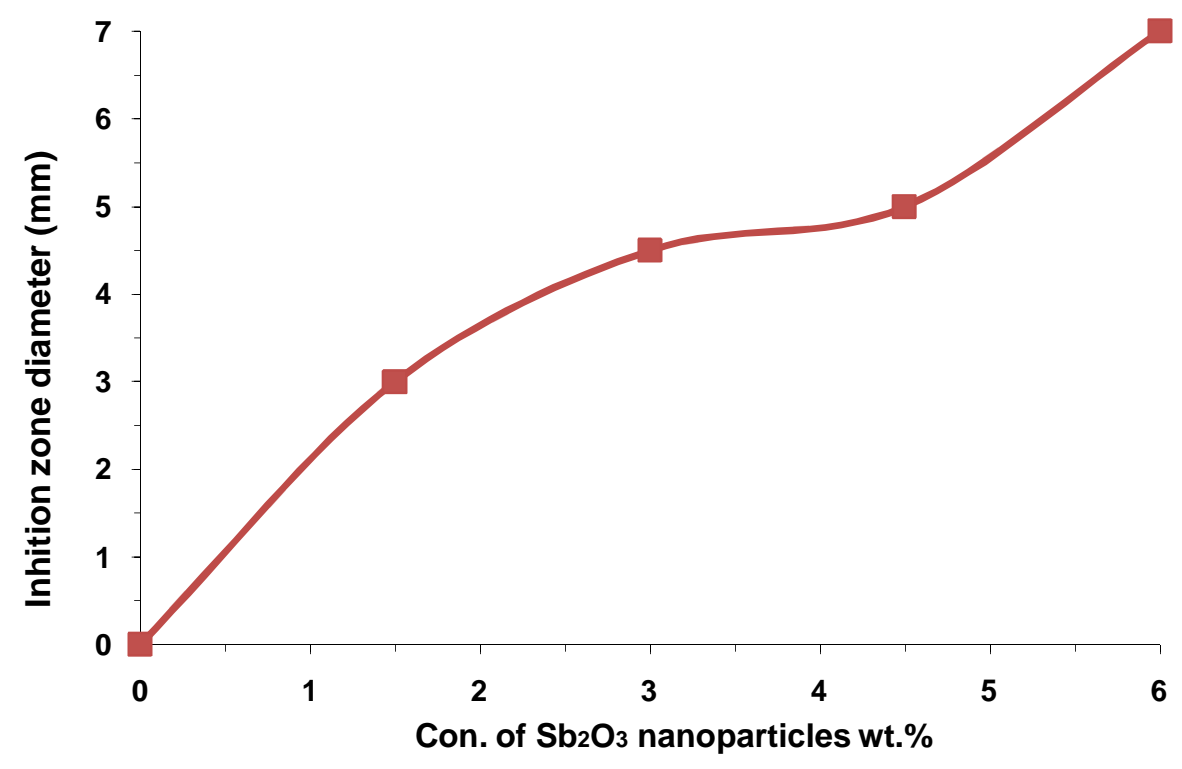

Figure 15: variation of inhibition zone diameter with $\mathrm{Sb}_{2} \mathrm{O}_{3}$ nanoparticles concentrations against E. coli for (PEO-PVA$\mathrm{Sb}_{2} \mathrm{O}_{3}$ ) nanocomposites. 